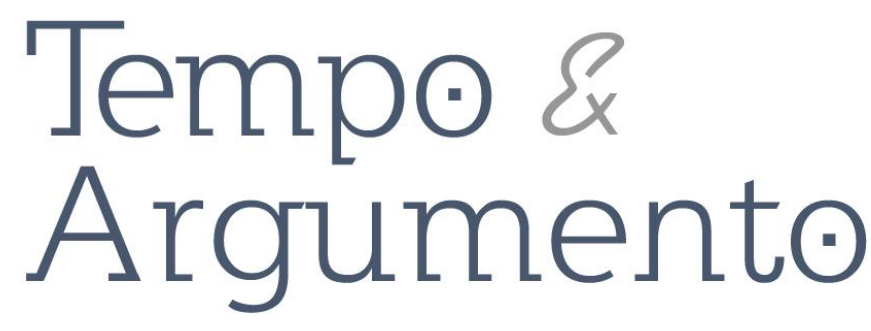

\title{
História do Tempo Presente e América Latina: Chile - uma entrevista com Cristina Moyano Barahona
}

\begin{abstract}
Entrevistada
A historiadora Cristina Moyano Barahona é docente de História e Geografia na Universidad de Santiago de Chile. Licenciada em Educação de História e Geografia (2000), com mestrado em História (2005) pela Universidad de Santiago de Chile. Obteve Doutorado em História (2007) pela Universidad de Chile, e realizou Pós-Doutorado no Instituto de Estudios Avanzados da Universidad de Santiago de Chile (2009). Trabalhou como professora convidada na Universidad Nacional de Tucumán (2015), na Argentina, e no Instituto Mora (2017-2018) no México. Tem como linhas de pesquisa os estudos em história contemporânea chilena, com foco nas elites políticas, esquerdas, militâncias e partidos políticos. É autora dos livros "El MAPU durante la dictadura. Saberes y prácticas para una microhistoria de la renovación socialista en Chile, 1973-1990", de 2010, e "Mapu o la seducción del poder y la juventud. Los años fundacionales del partido mito de nuestra transición. 1969-1973", de 2009. Atualmente, coordena o projeto de pesquisa "Usos políticos de la transición a la democracia. Ensayos políticos y demandas sociales en la construcción del tiempo histórico reciente, Chile 1986-2012", financiado pelo Proyecto Fondecyt.
\end{abstract}

Entrevista concedida em 12 de agosto de 2019.
Entrevistador

Carlos Eduardo Pereira de Oliveira

Doutorando em História pela Universidade do Estado de Santa Catarina (UDESC).

Florianópolis - SC - Brasil

kaduoliveira23@gmail.com orcid.org/0000-0003-0156-5460

\section{Para citar esta entrevista:}

MOYANO, Cristina. História do Tempo Presente e América Latina: Chile - uma entrevista com Cristina Moyano Barahona. [Entrevista realizada em 12 de agosto de 2019]. Revista Tempo e Argumento, Florianópolis, v. 11, n. 28, p. 528 - 533, set./dez. 2019. Entrevistador: Carlos Eduardo Pereira de Oliveira. 
Tempo e Argumento: ¿Cuál fue su trayectoria académica desde el inicio de sus estudios universitarios?

Cristina Moyano: Estudié en la Universidad de Santiago de Chile, como profesora de Estado en Historia y Geografía. Mi formación a comienzos de los años 90 estaba orientada a formalizar estudios para trabajar como profesora secundaria, sin embargo, pronto me di cuenta que mis intereses estaban puestos en la investigación y en más en particular, en los procesos de formación de identidad políticas. Así, terminado mi grado como licenciada en educación en historia y geografía, ingresé al magister en historia en la misma universidad, donde comencé a especializarme de manera más decidida en temáticas vinculadas a la historia política reciente.

Tempo e Argumento: ¿Cómo podría situar su producción académica dentro del escenario historiográfico de Chile?

Cristina Moyano: Mi obra historiográfica puede caracterizarse por los siguientes aspectos: 1. en primer lugar, es un trabajo historiográfico que ha venido a complementar el campo de la historia del tiempo presente o del pasado reciente, abordando aspectos referidos a culturas políticas de la izquierda. En ese sentido, he trabajado la conformación de identidades sociopolíticas de grupos como el Movimiento de Acción Popular Unitaria (MAPU) ${ }^{1}$ y los procesos de renovación de la izquierda socialista. 2. En segundo lugar, me he interesado por indagar en los procesos de reclutamiento y selección de líderes de la izquierda chilena, durante el período de Dictadura. Ambas cuestiones ligadas a la configuración de la cultura política de la transición chilena, elementos que permiten comprender la articulación intraelites, las dinámicas de representación, la construcción de legitimidad y otras cuestiones, de índole generacional y de mapas cognitivos que han sido preocupaciones en mis investigaciones.

\footnotetext{
${ }^{1}$ O Movimiento de Acción Popular Unitária (MAPU), foi um partido político de esquerda no Chile, dissidência do Partido da Democracia Cristã. Fez parte da Unidad Popular em 1970, participando ativamente do governo de Salvador Allende. Entra na clandestinidade após o golpe militar de 1973, voltando as atividades legalmente nos anos 1980.
} 
De forma vinculada a lo indicado previamente, también he investigado a los intelectuales-políticos que han colaborado a la producción de los universos simbólicos con los cuales las élites, pero también otros sectores sociales, se han representado el mundo en el que viven y desde los que actúan. En ese sentido, por ejemplo, recientemente desarrollé un proyecto de investigación que abordaba a los intelectuales y la producción de conocimiento social durante los años de la dictadura, particularmente aquellos que situados en centros de investigación independiente reflexionaron sobre la democracia, el estado, la sociedad civil, el poder, entre otras cuestiones claves sobre las que se montó el ideario transicional chileno ${ }^{2}$.

Tempo e Argumento: ¿Actualmente, ¿cuáles son los enfoques de sus trabajos?

Cristina Moyano: En términos de enfoques me defino de forma bastante ecléctica, buscando elementos teóricos tanto en la ciencia política, como en la sociología. En términos historiográficos comparto elementos provenientes de la historia conceptual y del lenguaje político, tanto en su versión inglesa como francesa, resultado de un mix que está más orientado a ser "eficaz" herramienta de análisis, que un corpus estricto de interpretación teórica. En ese plano también he trabajado con elementos provenientes de la teoría de redes y de la historia intelectual, complementando mis estudios con conceptos como los de espacio de sociabilidad, campo de saber y experticia, entre otros elementos relevantes.

Tempo e Argumento: ¿Cómo fue que la Historia del Tiempo Presente se volvió una preocupación en su carrera? ¿Cuáles fueron las referencias teórico-metodológicas que la influyeron en su proyecto de historizar el "tiempo presente"?

\footnotetext{
2 Investigadora responsável pelo projeto de pesquisa "Poder, prestigio y riqueza: transformaciones de la elite regional en el Gran Concepción: Del Estado desarrollista al Estado neoliberal, 1957-1990", financiado pelo Proyecto Fondecyt, sendo desenvolvido entre os anos de 2012 e 2014.
} 
Cristina Moyano: El tiempo presente ha sido para mi una preocupación permanente, siempre cruzado por mi interés en la historia política contemporánea. En particular creo que el hiato que generó el golpe de Estado y las profundas transformaciones de la dictadura nos abren una brecha en la que es imposible no pensar el presente como un campo de tiempo y espacio que no puede conectarse de forma tan tradicional como otros momentos de nuestra historia. La sociedad emergida después de la "revolución neoliberal" requiere de claves analíticas, de herramientas de investigación, de categorías conceptuales, entre otras cosas, que nos obligaron como historiadores a repensar las dimensiones de temporalidad e historicidad, por lo que resultaba urgente construir este campo de investigación, tomando las distancias de la investigación periodística de lo contemporáneo, pero compartiendo la idea de que el tiempo histórico vivido, coetáneo, debía ser revisitado, resituado para una adecuada comprensión de un presente extendido.

En términos de formación académica, yo provengo de una generación de historiadores en los que la historia social, la nueva historia social como se le llamó en Chile $^{3}$, marcó nuestras agendas, pero que suponía a la política como algo bastante ajeno al mundo popular. Sin embargo, la radicalidad de los cambios políticos experimentados no sólo como estudiantes universitarios, sino que como ciudadanos, nos volcó a este tiempo. En suma, como dirían los historiadores franceses, nos hicimos cargo de una demanda social por la historia, no patrimonializada, sino que crítica, dispuesta a competir por las representaciones del pasado reciente, normalmente relevado como "memoria".

\footnotetext{
3 "A chamada Nova História Social Chilena é uma corrente historiográfica que postula a necessidade de analisar os processos econômicos e sociais por uma ótica cultural, utilizando um foco 'desde abajo' e 'desde adentro'. Ou seja, tenta se inserir na vida cotidiana dos sujeitos comuns. Esse movimento historiográfico se produziu como resultado dos questionamentos políticos surgidos após o Golpe de Estado do general Augusto Pinochet em 1973, processo reforçado pela crise teórica que sofria o marxismo clássico a nível internacional desde então. Essa corrente implicou um processo revisionista e renovador que se realizou no exílio, e cujo principal palco foi a Revista Nueva Historia. Ademais, este foi influenciado pelas propostas do historiador britânico Edward Palmer Thompson". VERGARA, Gabriel Salazar. Nueva Historia Social. Disponível em: http://www.memoriachilena.gob.cl/602/w3-article-96428.html. Acesso em: 25 jul 2019. Tradução livre feita pelo autor.
} 
Tempo e Argumento: En el Brasil, durante algún tiempo, el campo de la historia del tiempo presente fue blanco de críticas, sobre todo en cuanto a los procedimientos del hacer historiográfico que implica. ¿Cómo se constituyó ese campo del saber en Chile? ¿Cuáles son los principales temas de investigación por los historiadores del "tiempo presente" en su país?

Cristina Moyano: No estoy tan segura que en Chile la historia del tiempo presente haya sido tan criticada. Las nuevas cohortes de historiadores se han concentrado en estas áreas y eso da cuenta de un campo de trabajo que tiene reconocimiento y que ha sido bastante bien aceptado por la comunidad de historiadores y por la sociedad en general. Quizás, esto pueda explicarse por la gran importancia que tuvo la renovación de la historiografía en los años 80 , que en el marco de la nueva historia social y de historiadores de izquierda, en centros académicos independientes, dotaron de legitimidad política a este mismo quehacer. Sin embargo, serán los historiadores formados en los años 90, en período de transición, donde este campo ha tenido mayor cantidad de cultores. Quizás se deba a cuestiones generacionales, pero también tiene relación con las disputas de la memoria, por el importante rol que la elite política concertacionista le dio a la misma historia y su relevancia para cuestionar la obra de la dictadura militar.

Hoy día en Chile podría decir que los ejes de los trabajos en historia reciente están concentrados en: a) militancias políticas; b) movimientos sociales; c) memoria y derechos humanos. Cuestiones, que podrán observar son bastante compartidas en toda América del Sur. De forma menos mayoritaria, pero no por ello menos relevante, han sido los estudios sobre culturas políticas en transición (fenómenos como el de la alcadización de la política), las transformaciones culturales neoliberales en el mundo popular y por cierto, movimientos sociales recientes.

Tempo e Argumento: En términos historiográficos, ¿existen diferencias entre la Historia del Tiempo Presente producida en Chile y en otros países latinoamericanos? 
Cristina Moyano: No creo que haya grandes diferencias entre la historia del tiempo presente en América Latina y del Sur. Hay espacios de sociabilidad compartidos, marcos analíticos y estrategias de recogimiento de información bastante compartidos, por lo que creo que las diferencias se inscriben más en los significados que tiene las obras en los distintos países, el impacto, la circulación, las revistas donde circulan, la incidencia en los curriculum escolares, etc. No veo con ello, cambios en el canon, formas escriturales o preguntas muy distintas, las cuestiones de la diferenciación quizás estén más puestos en la resonancia, en la capacidad de incidencia y ello, probablemente, vinculado al rol o lugar que tiene la historia en las distintas sociedades. 